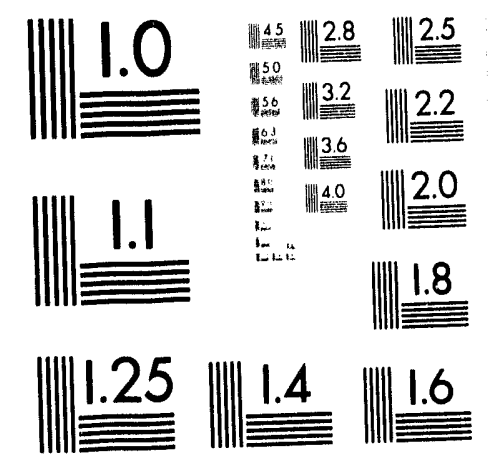



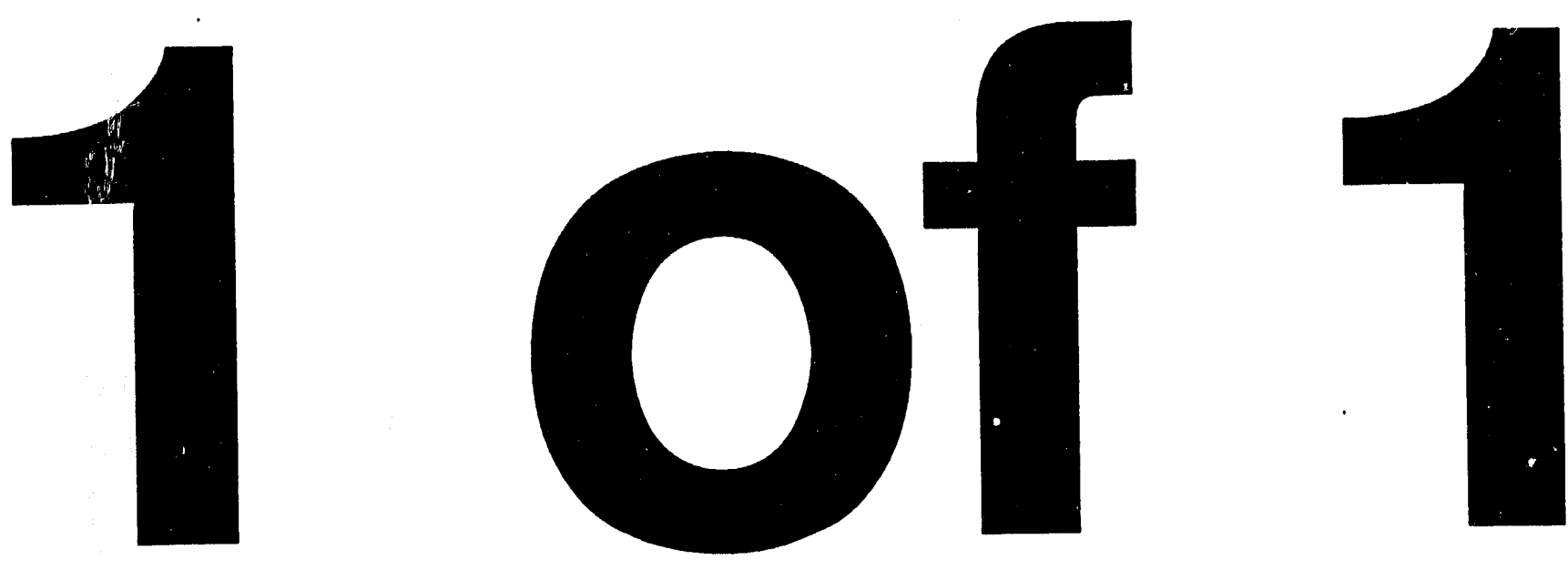
UCRL-JC-113779

PREPRINT

\section{INTERFACE SCIENCE OF CONTROLLED METAL/METAL AND METAL/CERAMIC INTERFACES PREPARED USING ULTRAHIGH VACUUM DIFFUSION BONDING}

\author{
WAYNE E. KING, G.H. CAMPBELL, \\ A.W. COOMBS, G.W. JOHNSON, \\ B.E. KELLY, T.C. REITZ, \\ S.L. STONER, W.L. WIEN \\ D.M. WILSON
}

This paper was prepared for submittal to the Materials Research Society

San Francisco, CA

April 12-16, 1993 i.

OCT 141993

OSTI

April 1993

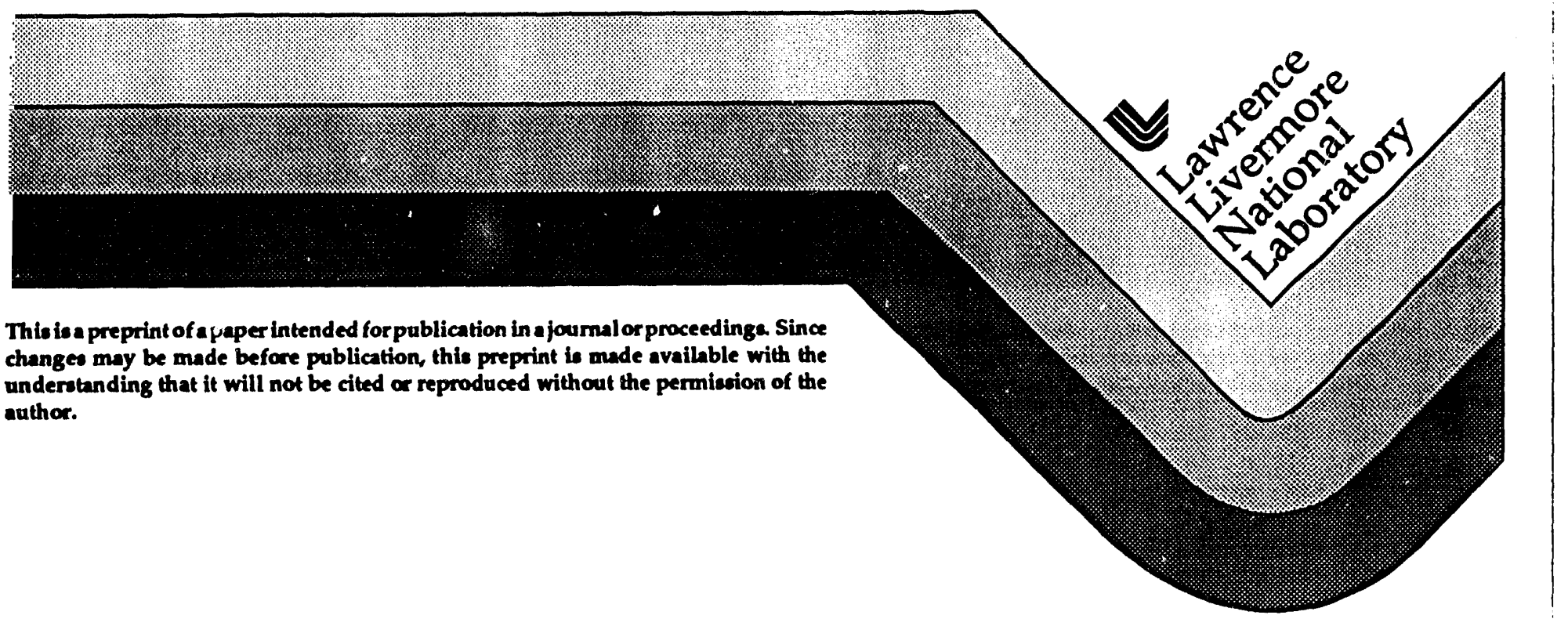




\section{DISCLAIMER}

This document was prepared as an account of work sponsored by an agency of the United States Government. Neither the United States Government nor the University of California nor any of their employees, makes any warranty, express or implied, or assumes any legal liability or responsibility for the accuracy, completeness, or usefulness of any information, apparatus, product, or process disdosed, or represents that its use would not infringe privately owned rights. Reference herein to any specific commercial products, process, or service by trade name, trademark, manufacturer, or otherwise, does not necessarily constitute or imply its endorsement, recommendation, or favoring by the United States Government or the University of California. The views and opinions of authors expressed herein do not necessarily state or reflect those of the United States Government or the University of California, and shall not be used for advertising or product endorsement purposes. 


\title{
INTERFACE SCIENCE OF CONTROLLED METAL/METAL AND METAL/CERAMIC INTERFACES PREPARED USING ULTRAHIGH VACUUM DIFFUSION BONDING
}

\author{
WAYNE E. KING, G. H. CAMPBELL, A. W. COOMBS, G. W. JOHNSON, B. E. KELLY, \\ T. C. REITZ, S. L. STONER, W. L. WIEN, AND D. M. WILSON \\ Chemistry and Materials Science Department, University of California, Lawrence Livermore \\ National Laboratory, Livermore, CA 94550
}

\begin{abstract}
We have designed, constructed, and are operating a unique capability for the production of highly controlled homophase and heterophase interfaces: an ultrahigh vacuum diffusion bonding machine. This machine is based on a previous design which is operating at the Max Planck Instirut fur Metallforschung, Institut für Werkstoffwissenschaft, Stuttgart, FRG. In this method, flat-polished single or polycrystals of materials with controlled surface topography can be heat treated up to $1500^{\circ} \mathrm{C}$ in ultrahigh vacuum. Surfaces of annealed samples can be sputter cleaned and characterized prior to bonding. Samples can then be precisely aligned crystallographically to obtain desired grain boundary misorientations. Material couples can then be bonded at temperatures up to $1500^{\circ} \mathrm{C}$ and pressures up to $10 \mathrm{MPa}$. Results are presented from our initial work on Mo grain boundaries and $\mathrm{Cu} / \mathrm{Al}_{2} \mathrm{O}_{3}$ interfaces.
\end{abstract}

\section{INTRODUCTION}

The lack of well characterized, precisely oriented interfaces has been identified as limiting the capability of the Interface Science community to make progress in the study of structure and properties of interfaces. Lawrence Livermore National Laboratory and Sandia National Laboratories are developing a multi-disciplinary, multi-institutional research effort in interface science. This research, which focuses on the influence of impurities, flaws, and inclusions on adhesion and bonding at intemal interfaces will rely on the availability of bicrystals with well defined interfacial chemistry and highly reproducible misorientations. The capability to produce such bicrystals did not exist within the United States although it is critical to further advancement of interface science and technology.

\section{BACKGROUND}

To address this need we have selected the diffusion bonding approach, which was successfully demonstrated at the Max Planck Institut in Stuttgart, for application to the class of interface problems of interest. ${ }^{1,2}$ Figure 1 shows a rendering of the design of the UHV diffusion bonding machine. It comprises four chambers: a surface analysis chamber, a diffusion bonding chamber, an annealing chamber, and a surface modification chamber (not showri). typically, a sample is first introduced into the annealing chamber via either an airlock chamber (Figure 2). The sample is annealed in ultrahigh vacuum to $1500^{\circ} \mathrm{C}$ to stabilize the microstructure.

After annealing, a rail system transports the sample to the surface analysis chamber, to the surface modification chamber, or to the bonding chamber. A special manipulator (see the Figure 3) moves the sample to the railroad car. In the surface analysis chamber (Figure 4), sample surfaces are sputter-cleaned with a $500 \mathrm{eV}$ ion beam at an incidence of $15 \mathrm{deg}$. The sample can be rotated during sputtering to ensure that material is removed uniformly. The sample can be heated at the same time to about $1000^{\circ} \mathrm{C}$ to purify its near-surface region. Surface cleanliness and levels of surface doping are assessed with Auger electron spectroscopy, low-energy electron diffraction, and static secondary-ion mass spectrometry.

In the surface modification chamber (planned for 1994), the sample can be rotated to face a low-energy ion implanter. The implanter has two ion sources to provide both gas and other ions. The sample can be further rotated to face an electron-beam evaporator or a magnetron sputtering source, where it can be 


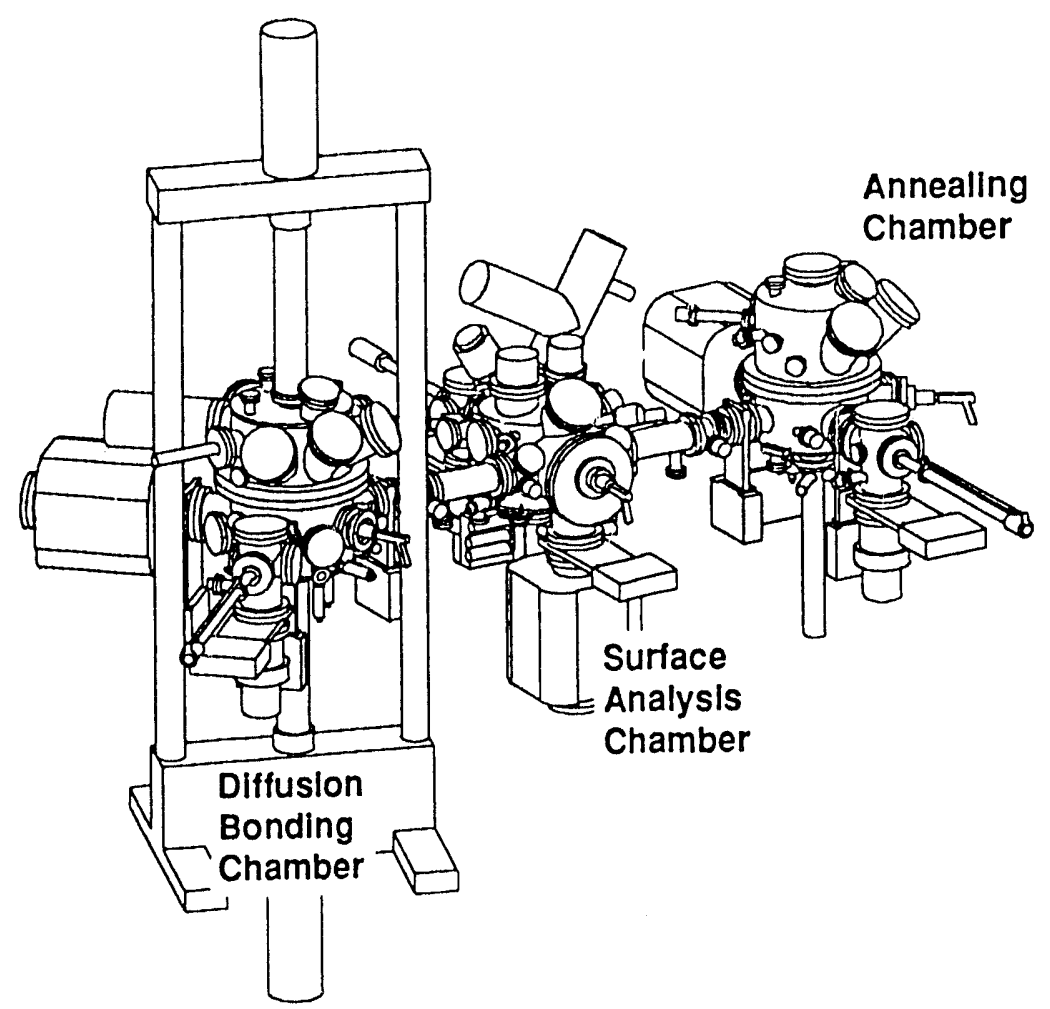

Figure 1. Rendering of the Lawrence Livermore National Laboratory UHV Diffusion Bonding Machine.

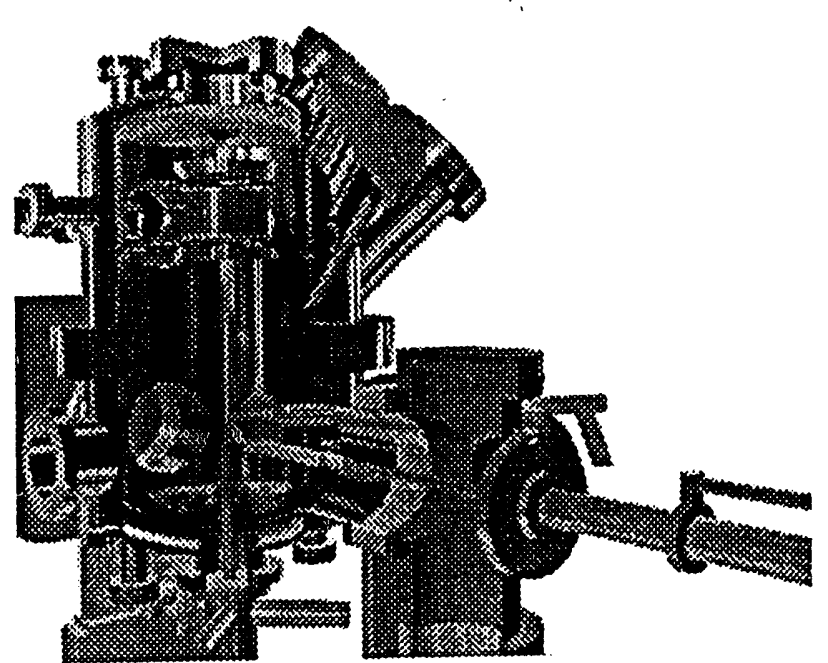

Figure 2. Cut-away view of the annealing chamber. Air-lock chamber is shown at right. Radio frequency (RF) furnace is shown at top center.

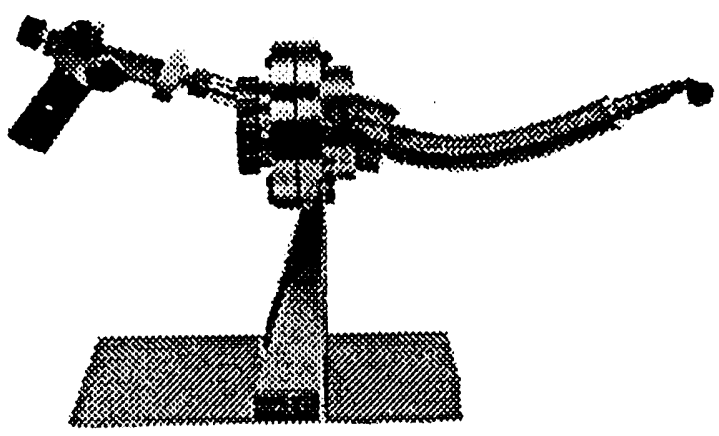

Figure 3. Multi-articulated manipulator for manipulating samples in vacuum without sample holder. The mechanical hand at the end of the arm is shown grasping a coin.

loaded onto a heated sample holder. An airlock is included in the surface-modification chamber for loading and unloading samples.

In the bonding chamber (Figure 5), samples are stacked on the lower ram of the diffusion bonding press. A spacer is first placed on the ram and fixed with a set of fingers on a precision crystal-orientation device (Figure 6). The first sample is stacked onto the spacer, and another set of fingers is driven in to hold the sample. The next sample is placed on top of the first sample and fixed with a third set of fingers. Finally, a second spacer is stacked on the top of the samples and positioned by a final set of fingers. 


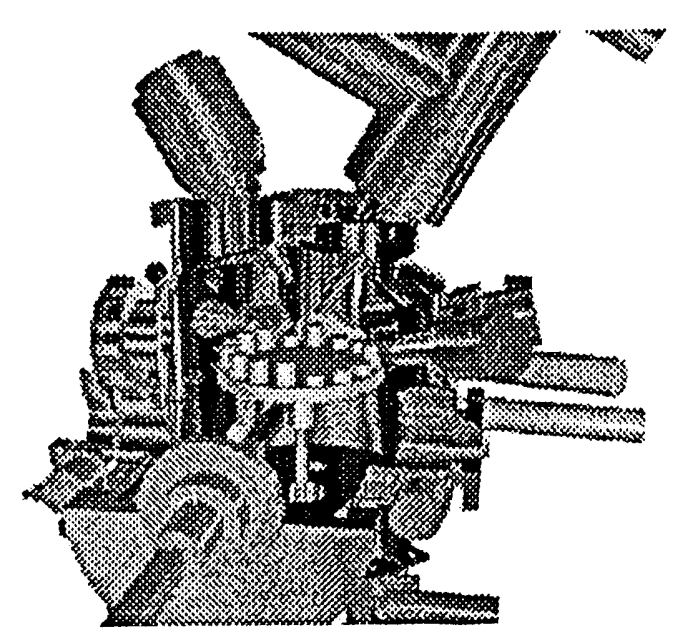

Figure 4. Cut-away view of the surface analysis chamber.SIMS ion gun is shown at top left. SIMS quardupole mass spectrometer is shown at top right.

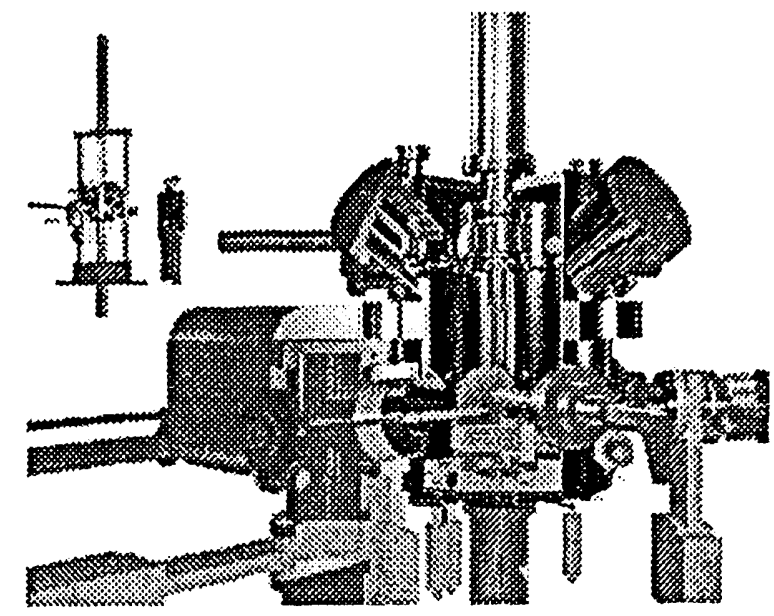

Figure 5. Cut-away view of the diffusion bonding chamber. Bonding chamber and press are shown at top left.

A laser beam is then reflected off the edge of the bottom sample in the stack. The sample is rotated with the precision crystal orientation device until a prepolished optical flat reflects the laser beam through a port of the diffusion bonding chamber onto a screen. The position of the reflection is noted, and the laser beam is then raised to intersect the upper sample. This sample is rotated so that the reflection from itsoptical flat coincides with the reflection from the bottom sample. The rotation gears of the precision crystal orientation device are locked, and the upper ram is brought to bear upon the sample stack. A small load is added, and the fingers are withdrawn. The entire stack is then raised into the furnace for bonding. An airlock is also incorporated in the diffusion bonding chambe $i$ to facilitate removal of bonded samples.

\section{RESULTS AND DISCUSSION}

\section{Fracture of the Cu/Alumina interface}

We have fabricated samples intended for fracture testing using the Ultrahigh Vacuum Diffusion Bonding Machine. These samples were diffusion bonds of polycrystalline high purity copper foils, $\sim 200 \mu \mathrm{m}$ thick, to high purity polycrystalline alumina rods, $2.0 \mathrm{~cm}$ long. The foil geometry was selected to minimize the contribution of bulk plasticity to the fracture-resistance measurements. Surfaces of the copper foils and aiumina rods were sputter cleaned insitu prior to bonding. Bonding was carried out as a function of temperature $\left(800,875\right.$, or $\left.960^{\circ} \mathrm{C}\right)$ and time

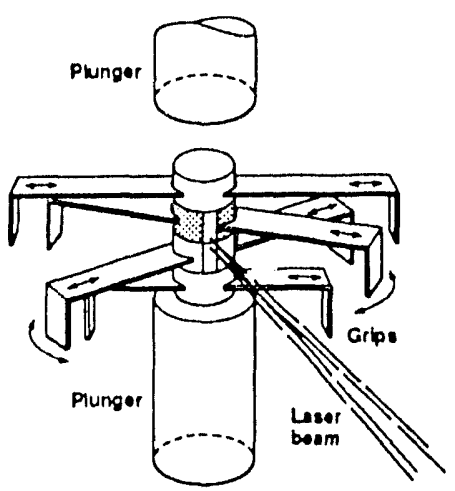

Figure 6. Schematic diagram of precision crystal orientation device. ( 1 or 2 hours) at a bonding load of $1.0 \mathrm{MPa}$. Resultant bonded samples yielded seven 4 point bend test samples.

Figure 7 demonstrates how this geometry was fabricated such that it could be bonded in ultrahigh vacuum where the samples are handled remotely without sample holders. The pieces at left are the starting materials, flat-polished alumina rods, a thin Cu foil, and a support ring for the copper foil. Two support rings are spot welded to the rim of the $\mathrm{Cu}$ foil. This support ring facilitates the remote handling of the samples in the ultrahigh vacuum. The bonding process proceeded as follows: First an alumina rod was loaded into the 


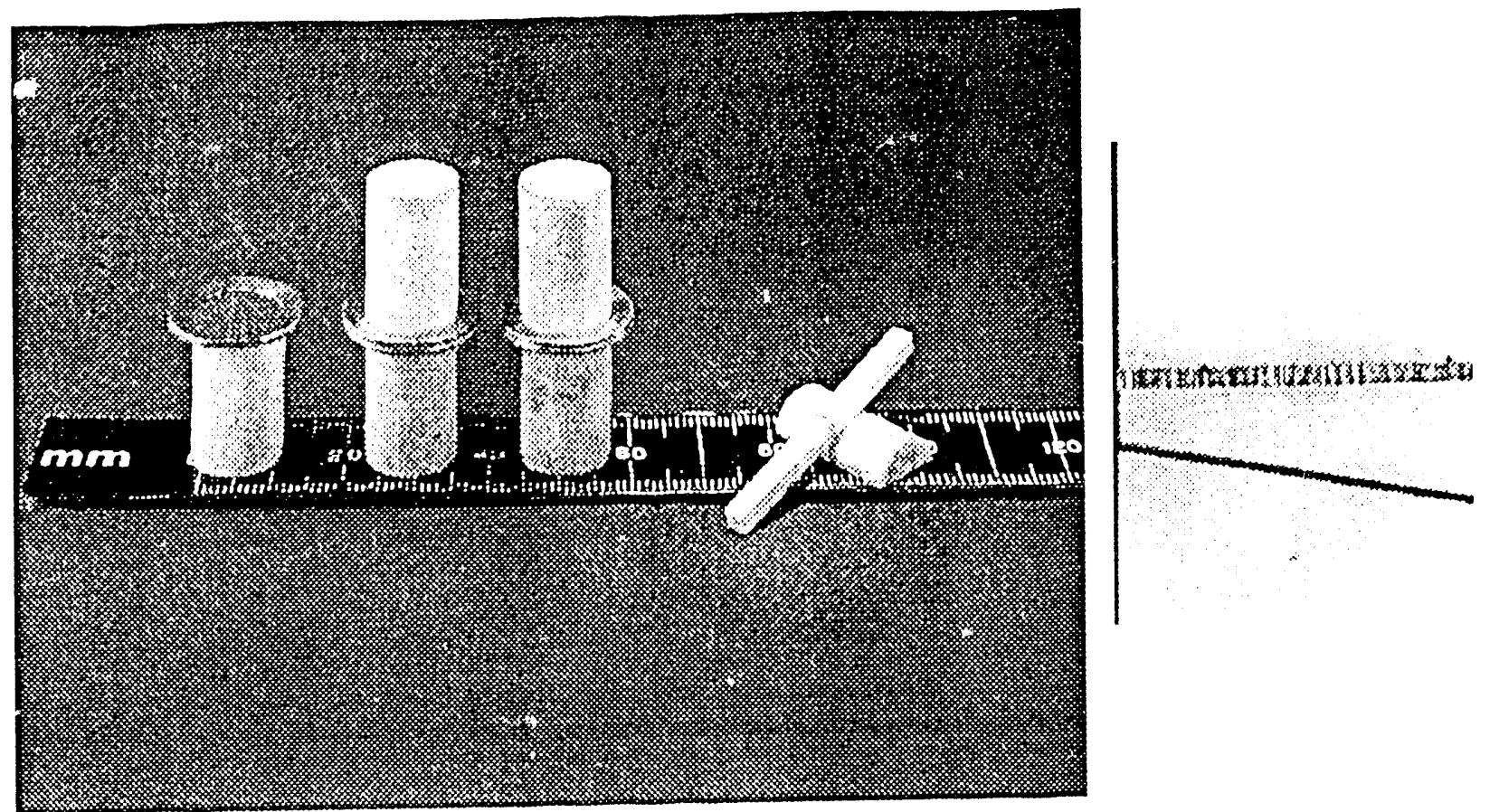

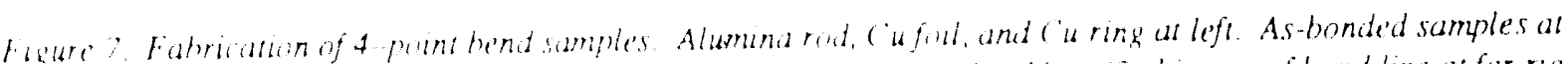

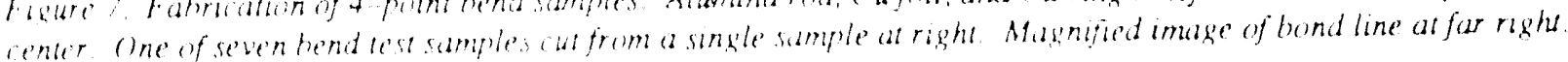

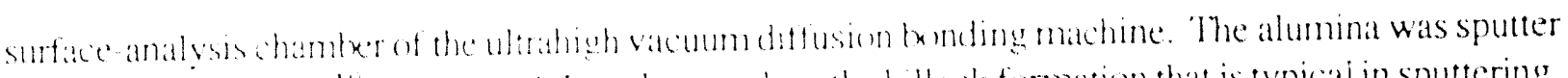

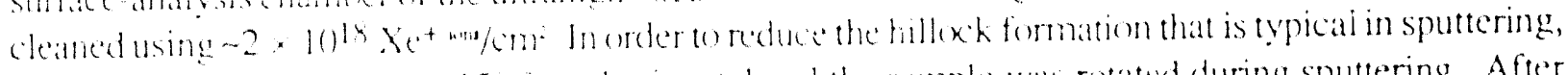
the inn txam was inchent at 15 from herizontal and the sample was rotated during sputtering. After cleaming, the altamina was transfered to the diffusion bondmg chamber and loaded on the lower ram of

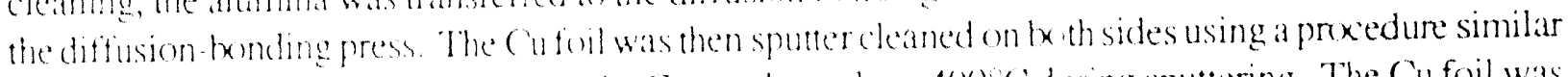
to that used for the aluminat exept that the Cu was heated $(1-a t(x)$ ( during sputtering. The Cu foil was statked atop the first alumina ret in the diffusion bending chanber. Finally, the second alumina bas was cleanced and the sample stack wis completed. A load of 1 .6 MPa was applied to the stack and the stack was raised into the radio frequency heater in the diffusion tonding chamber. The temperature was ramped (1) the set point over 25 min followed by the soak time and then ramped back to rom temperature over

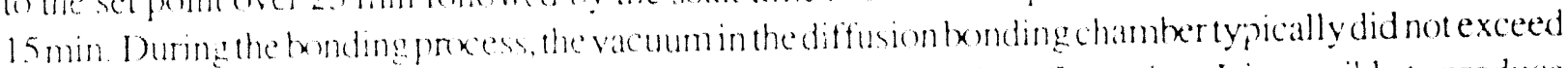

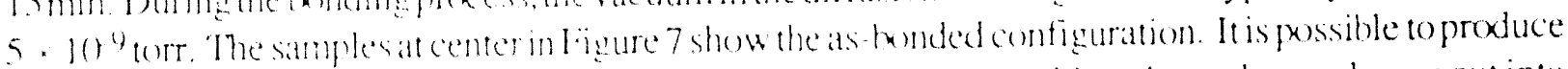
1-2 samples per day of this type. Alter removal from the txonding machine, the each simple was cut into

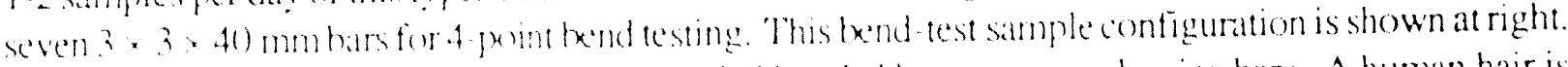

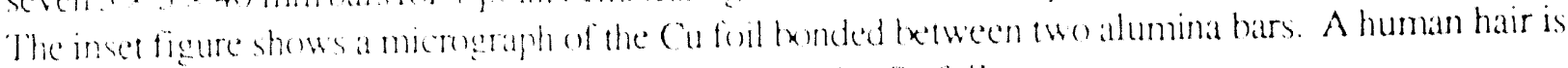
incluked in the micregraph illustrating the thimness of the Cu foil

Samplesweremtehedfor 4 print tendestingusingahigh-speedsaw. Notcheswerecut 0.5 mmdeep

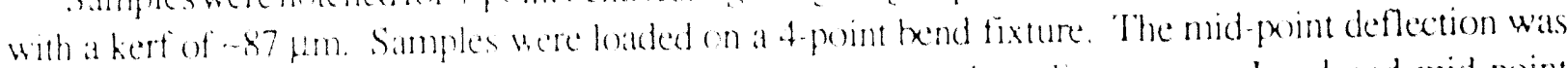
montured using a spring toated prote fitted with two oppesing clip gituges. I a ad and mid-point disphement were monitured as at function of thme fir a constant cross head displatement rate. Figure

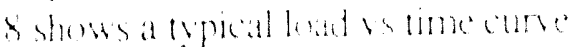

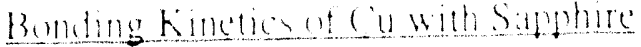

To determine the comblitums under which completely dense interfices form, we are studying the evolution of txonded interfacial area as a function of tending temperanure and time. The system under

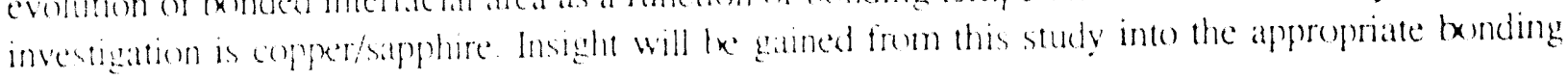




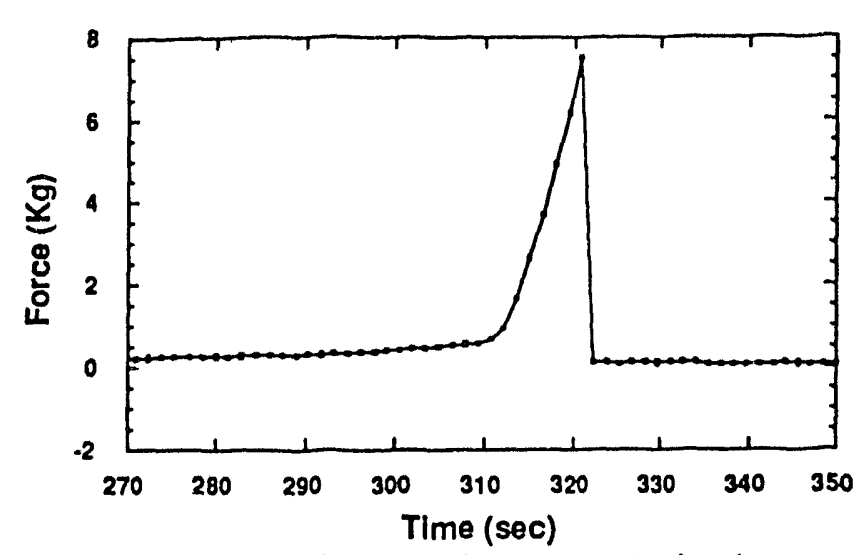

Figure 8. Typical load vs, time data for 4-point bend sample shown in Figure 7. conditions for copper/alumina mechanical test specimens and data will be obtained on a model system in diffusion bonding.

In the analysis chamber of the UHV Diffusion Bonding Machine, the surfaces of the specimens to be bonded were cleaned by ion sputtering with $\mathrm{Xe}^{+}$ions at $1 \mathrm{keV}$. The samples were rotated during sputtering to maintain an even surface finish. The cleaned surfaces were placed together in the bonding chamber and high purity alumina spacer blocks inserted between the specimens and the rams of the hydraulic press. To ensure proper alignment of the specimen stack so that the applied force is distributed as an uniform pressure on the bond area, the top spacer block had a spherical radius of curvature ground on one end to allow point contact with the top ram. The applied force resulter in a pressure of $1 \mathrm{MPa}$ at the bonding interface in all cases studied here.

The bonding temperature and times were varied to study their effects. The temperatures chosen were 800,900 , and $1000^{\circ} \mathrm{C}$ and the times were 1,2 , and $4 \mathrm{hr}$. During the diffusion bonding heat cycle the pressure in the bonding chamber never exceeded $1 \times 10^{-8}$ torr. The heating and cooling rates were 20 and $15^{\circ} \mathrm{Cl}$ min, respectively.

The characterization of the bonded area at the interface was done by optical microscopy through the sapphire. Under normal incidence light conditions, the bonded areas are light in contrast because the copper is conforming to the polished surface of the sapphire and reflecting light back into the objective. The micrographs were digitized and a brightness threshold was chosen for each micrograph which corresponded with the bonded area. The number of pixels above this brightness was summed and an area fraction was calculated.

Some results are shown in the in Figure $9 a$ and $b$. The average measured bonded area is shown along with the high and low measures indicating the variability in bonded area density across the entire interface. The results indicate that achieving a fully dense interface in the copper/alumina system requires lengthy bonding times, probably 6 to $12 \mathrm{hr}$, at $1000^{\circ} \mathrm{C}$ or higher.

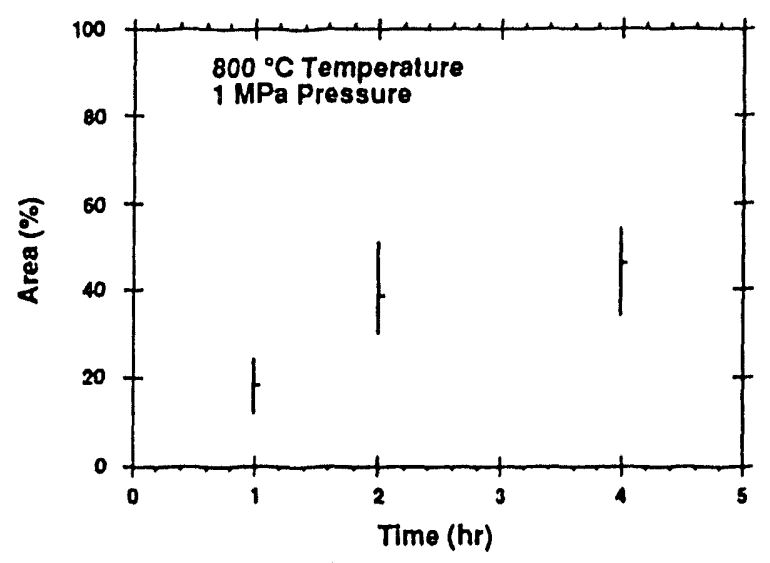

Figure 9a. Fractional bonded area as a function of time for constant temperature and pressure.

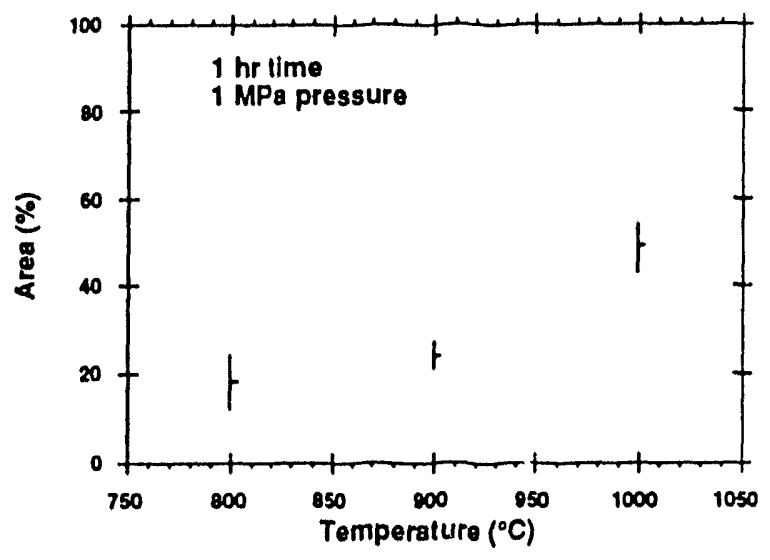

Figure $9 b$. Fractional bonded area as a function of temperature for constant time and pressure. 
In this experiment, $\sim 50 \AA$ of Ti was sputter deposited on a piece of sapphire. The Ti was then covered with $\sim 2 \mu \mathrm{m}$ of $\mathrm{Cu}$. The samples were removed from the sputter deposition machine and loaded into the ultrahigh vacuum diffusion bonding machine. Bulk polycrystalline oxygen-free high conductivity copper was bonded to the coated sapphire. Surfaces of the copper and coated sapphire were sputter cleaned insitu prior to bonding. Bonding was carried out as at $800^{\circ} \mathrm{C}$ for 1 hour at a bonding load of $1.0 \mathrm{MPa}$. Resultant bonded sample was cut into the appropriate geometry for analytical electron optical observation. The Figure 10 shows a cross-section electron micrograph of the bonded interface inset within the x-ray energy dispersive spectroscopy profile.

\section{Mo Bicrystals}

We have fabricated two bicrystals intended for grain boundary atomic-structure determination using the Ultrahigh Vacuum Diffusion Bonding Machine. This sample was a diffusion bond of a pair of Mo single crystals. The Mo single crystals were oriented along $\langle 310\rangle$, sliced parallel to the (310) plane, and flat polished and precisely oriented to within $0.1^{\circ}$ of $(310)$.

The rate of diffusion bonding is controlled by surface diffusion which is a function of temperature and pressure. We seek interfaces with controlled geometries (usually planar) and chemistries. Such interfaces can only be obtained by minimizing the temperature, pressure, and time for diffusion bonding in order to discourage boundary migration, deformation, and segregation of impurities to the interface. A key to reducing bonding temperature, pressure, and time is the minimization of the volume of materials that must be transported by surface diffusion in order to eliminate porosity at the interface. This has been accomplished by controlling the flatness of the surface of the samples to be bonded. Typical metallographic preparation methods yield samples with peak-to-valley deviations from flatness of $\sim 1000 \mathrm{~nm}$. This flatness has been significantly improved, $<100 \mathrm{~nm}$, by using techniques used in the polishing of precision optics, namely pitch polishing.

Surfaces of the Mo single crystals were sputter cleaned in-situ prior to bonding. Bonding was carried out at $1400^{\circ} \mathrm{C}$ for four hours at a bonding load of $1.0 \mathrm{MPa}$. The bicrystal was aligned and bonded as described above. Resultant samples were be cut into the appropriate configuration for observation in the high resolution electron microscope. A high resolution image taken on the JEOL $4000 \mathrm{EX}$ at SNL, L from a suitably thin area of a specimen (Figure

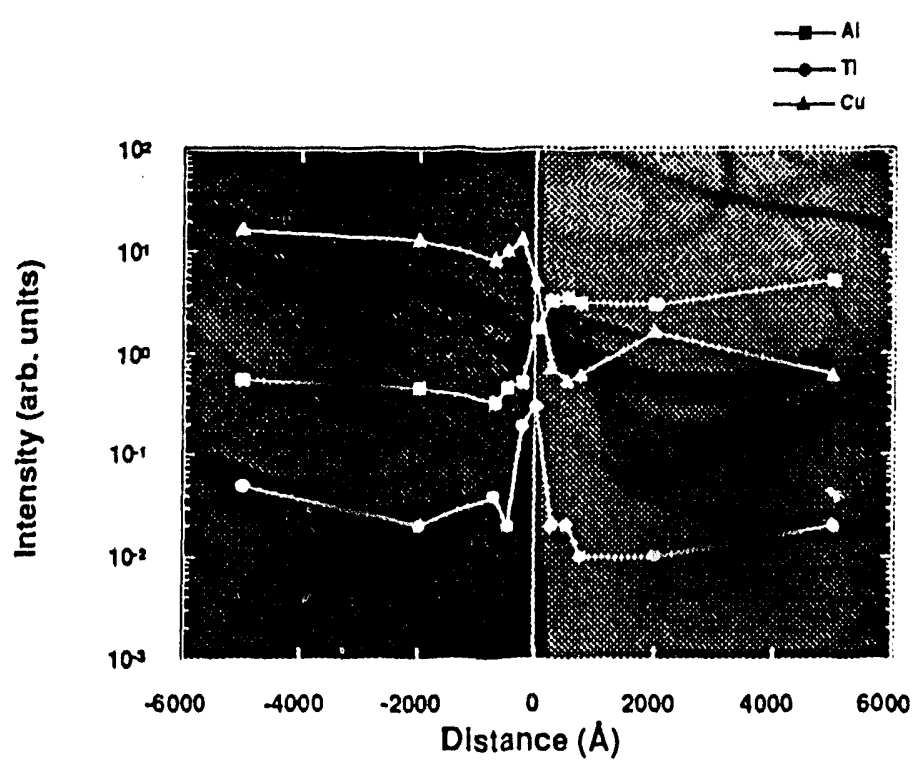

Figure 10. X-ray energy dispersive spectroscopy trace of $A l, T i$, and $C u K \alpha x$-rays as a function of position relative to the interface between $C u$ (at left in inset electron micrograph) and sapphire (at right).
$11 \mathrm{a})$ is shown in Figure 11b. The boundary is a symmetric tilt boundary with [001] tilt axis which forms a twin about the (310) plane. The high resolution image in Figure $11 \mathrm{~b}$ repesents a projection of the atomic structure, in this case, parallel to the tilt axis. The high resolution image is especially well suited to revealing any rigid body translations present between the crystals at the boundary, which is a common feature of EAM structure predictions. Further structural details are compared to predicted structure by using those structures in high resolution image simulations, as discussed earlier. 


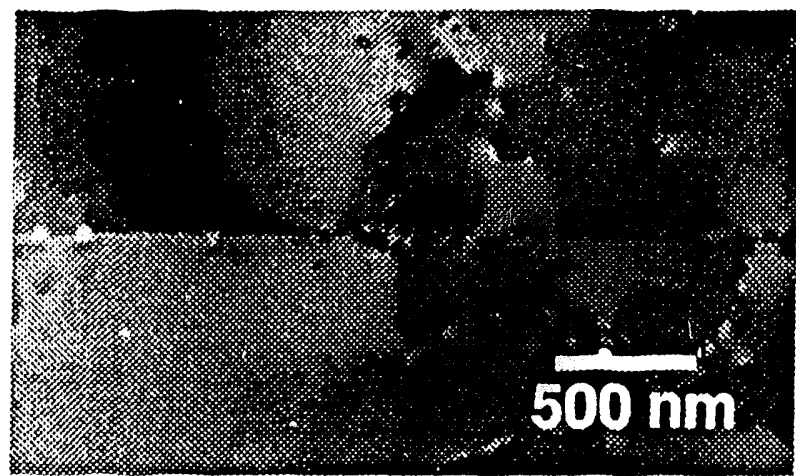

Figure 1la. Low magnification image of Mo bicrystal illustrating long flat regions of interface.

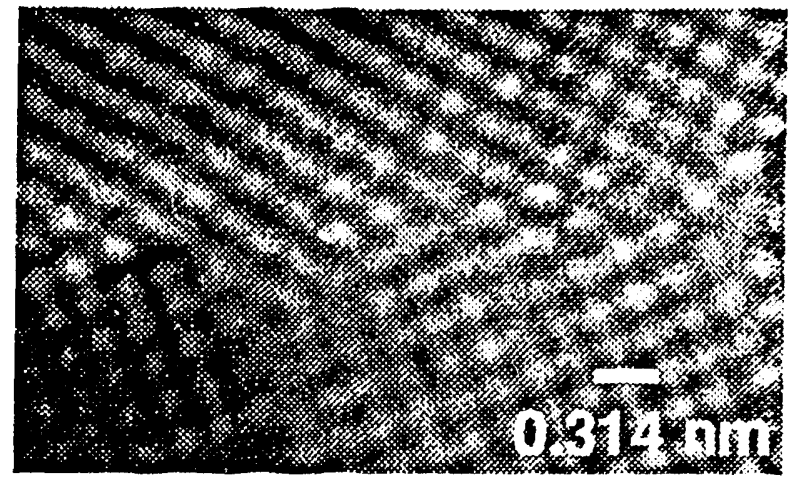

Figure llb. HREM image from section of interface in Figure lla.

\section{CONCLUSIONS}

The new ultrahigh vacuum diffusion bonding machine offers a number of new opportunities in the study of interface science:

- Controlled interface crystallography can be used to carefully investigate interface atomic structure

- Controlled interface topography can be used to investigate the effect of flaws on interfacial toughness

- Controlled interface chemistry can be used to study the effect of impurities on interfacial adhesion and bonding

- Macroscopic bicrystals (as opposed to thin films) can be used to carry out mechanical tests as well as for validation of theoretical predictions of atomic structure

- Homophase boundaries (e.g. grain boundaries in metals, intermetallics, or ceramics) and heterophase boundaries (e.g. metal/ceramic interfaces, metal/semiconductor interfaces) can be produced

\section{ACKNOWLEDGMENTS}

The authors are grateful for the great contributions of Prof. Dr. H. Fischmeister and Prof. Dr. M. Rühle at the Max Planck Institut für Metallforschung, Institut für Werkstoff wissenschaft in Stuttgart to the design of the UHBV diffusion bonding machine. We are also grateful to $\mathrm{M}$. Wall for assistance with electron microscopy of $\mathrm{Cu} /$ alumina interfaces. This work performed under the auspices of the Division of Materials Science of the Office of Basic Energy Sciences, U. S. Department of Energy, and the Lawrence Livermore National Laboratory under contract No. W-7405-Eng-48.

\section{REFERENCES}

1. B. Gibbesch and G. Elssner, Acta metall. mater., 40 (Suppl.), S59-S66, (1992).

2. H. F. Fischmeister, W. Mader, B. Gibbesch and G. Elssner in Interfacial Structure. Properties and Design, edited by M. H. Yoo, W. A. T. Clark and C. L. Briant (Mater. Res. Soc. Symp. Proc. 122, Pittsburgh, PA 1988) pp. 529-540. 

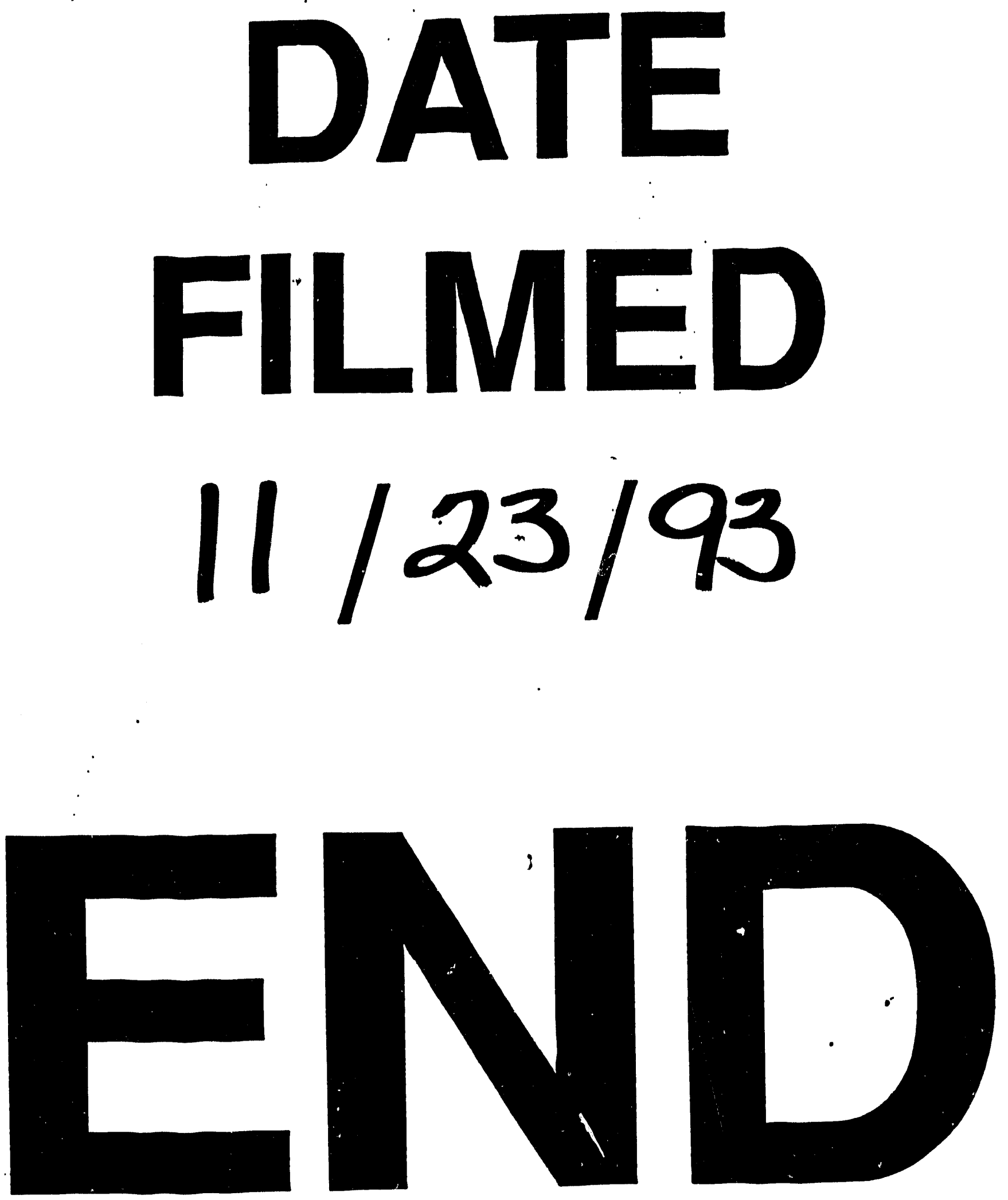


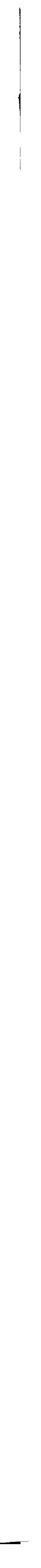

